\title{
LUGAR DO LÉXICO NO DESENVOLVIMENTO DO ENSINO E DA CAPACIDADE LEITORA
}

\author{
Symara Abrantes Albuquerque de Oliveira Cabral ${ }^{1}$ \\ Sayonara Abrantes de Oliveira Uchoa ${ }^{2}$
}

\section{RESUMO}

Este trabalho objetiva discutir a importância de processos de ensino de leitura pautados nas relações lexicais como metodologia eficiente ao desenvolvimento da competência leitora. Trata-se, pois, de um estudo exploratório-descritivo, fundamentado teoricamente em recorte de pesquisa de Doutoramento e em contribuições que se entrecruzam das áreas da Linguística, Psicologia e Pedagogia. Os resultados apontam para a eficiência da construção de paradigmas de ensino de leitura pautados no léxico como contributos ao desenvolvimento de um leitor autônomo.

Palavras-chave: léxico; leitura; competência leitora.

\section{THE ROLE OF LEXICON IN THE TEACHING OF READING AND IN THE DEVELOPMENT OF READING SKILLS}

\section{ABSTRACT}

This paper aims at discussing the teaching of reading based on lexical relations as an efficient methodology for the development of reading skills. It is, therefore, an exploratory-descriptive study based on a doctoral research in which contributions of the fields of Linguistics, Psychology and Pedagogy are intertwined. Results point out that lexicon-based teaching contributes to the development of autonomous readers.

Keywords: lexicon; reading; reading skills.

Recebido em: $14 / 4 / 2019$

Aceito em: 21/6/2020

${ }_{1}$ Universidade Estadual do Rio Grande do Norte. http://lattes.cnpq.br/9308542814186010. https://orcid.org/0000-0002-7456-5886.

2 Autora correspondente. Instituto Federal de Educação, Ciência e Tecnologia da Paraíba - Campus Cajazeiras. Rua José Antonio da Silva, 300 - Jardim Oásis. Cajazeiras/PB, Brasil. CEP 58900-000. http://lattes.cnpq.br/8483738213524765. https://orcid.org/0000-0001-63912005. sayonara_abrantes@hotmail.com 


\section{INTRODUÇÃO}

Em uma sociedade cujas interações são intermediadas pela linguagem, ler e compreender são condições para se "estar e se fazer" em um mundo letrado, visto que o ato de ler diz respeito à condição de interagir no mundo (DE BORTOLLI, 2002). É necessário deixar claro, no entanto, que, embora a linguagem constitua este universo de dimensões incomensuráveis, não se pode afirmar que, a partir de sua aquisição, o falante, automaticamente, adquire possibilidades infinitas, visto que a linguagem constitui-se por uma sistematização aberta, histórica e socialmente produzida (GERALDI, 1997).

Nesse contexto, decorrentes das concepções de linguagem, surgem visões diferenciadas que estabelecem concepções sobre leitura, de acordo com diferentes correntes teóricas e, por isso, direcionamentos para o seu desenvolvimento. Dessa forma, ler não pode ser compreendido numa dimensão simplista, visto que agrega aspectos de alta complexidade e, por sua função social, requer a construção de padrões por parte do leitor para que possa mergulhar nas diversas fases desse processo, transcendendo da mais simples para a mais complexa.

Sob essa dimensão, discutiremos as concepções de leitura voltando-nos para a análise dos contributos teóricos e à configuração do que vem a ser um leitor competente linguisticamente, sob diferentes visões teóricas, visando a situar aquela que atende a este estudo voltando-se à importância dos aspectos lexicais mobilizados no ato de ler, defendendo, com base em cada uma das vertentes teóricas nas quais nos fundamentamos a importância de um entroncamento entre elas, ou seja, os pontos de intersecção que irão contribuir para a defesa em pauta, por meio da análise minuciosa da percepção dos fenômenos lexicais nos descritores de Língua Portuguesa.

Esse situar teórico das diferentes concepções de leitura e de seu ensino estabelece a base para a análise da importância do olhar lexical sobre esses processos de modo a constituir práticas educativas, por meio das quais os alunos constituam-se leitores capazes de agir e interagir com e pela linguagem. Ressaltamos, no entanto, que não situaremos discussões em aspectos relativos ao processo e aquisição da linguagem, visto não ser esse o foco. Por outro lado, buscaremos discutir as concepções de leitura numa vertente mais voltada para o desenvolvimento da capacidade leitora, conceito no qual nos deteremos com mais profundidade no decorrer do estudo.

\section{DAS CONCEPÇÕES DE LEITURA ÀS CONTRIBUIÇÕES DO LÉXICO PARA A LEITURA}

Tomando por escopo a importância atribuída à leitura, passamos a analisar teorias ou modelos teóricos que subsidiam as discussões sobre os conceitos e o desenvolvimento do ato de ler e, por um viés cognitivo, de base Psicolinguística e Sociopsicolinguística, Kato (2007) e Solé (1998) apresentam os modelos teóricos direcionadores do processamento da informação por meio da leitura, apresentando-os como o modelo ascendente e/ou bottom-up, o modelo descendente e/ou top-down e o modelo interativo. 
A partir de uma visão do processamento textual, ou seja, ancorados nos paradigmas da Linguística do Texto ou Linguística Textual, Kleiman (1999; 2011), Koch (2011), Koch e Elias (2011), Polessi e Menegassi (2010) apontam para perspectivas que delimitam as concepções de leitura com base na visão de sujeito, de língua, de texto e de sentido: a Perspectiva do Texto, a Perspectiva do Leitor e a Perspectiva Interacionista. Somando-se às perspectivas já apresentadas, Orlandi (2012) e Coracini (2002), sob os postulados da Análise do Discurso, referenciam à Perspectiva Discursiva. Com relação a essa perspectiva, para Orlandi (2012, p. 58), “Uma leitura não é possível e/ou razoável em si, mas em relação às suas histórias. Assim, não há leituras previstas por um texto, em geral, como se o texto fosse um objeto fechado em si mesmo". Por acreditarmos no aspecto da previsibilidade dos sentidos no texto, não adotamos a concepção discursiva (UCHOA, 2013, p. 19), motivo pelo qual nos aprofundaremos somente nas demais perspectivas.

Ressaltamos que o propósito deste estudo é refletir sobre as especificidades dos modelos teóricos definidos pela Perspectiva do Texto, pela Perspectiva do Leitor e pela Perspectiva Interacionista, bem como pelo Modelo Ascendente e/ou bottom-up, Modelo Descendente e/ou top-down e pelo Modelo Interativo - que fundamentam o olhar sobre ensino da leitura como ferramenta linguística. Acerca dessas vertentes a serem analisadas, é necessário deixar claro, de antemão, que as teorias aqui abordadas não serão analisadas em uma perspectiva excludente. Ao contrário, com base nos aspectos defendidos em cada uma delas, podem ser consideradas modelos teóricos semelhantes, complementares, visto que carregam aspectos relevantes à percepção dos percursos para o desenvolvimento do ensino de leitura.

O modelo ascendente (bottom-up) (KATO, 2007), também referido como modelo de processamento (Kleiman, 1998), modelo sequencial (Micotti, 2012) ou modelo baseado em dados (KATO, 2007), é defendido teoricamente por Gough (1972) e Kolers (1975) e consiste numa visão cujo processamento ocorre de modo linear e indutivo, partindo, pois, de uma abordagem composicional por meio da qual os significados são o produto da síntese do significado das partes que compõem o texto (KATO, 2007). Nesse, o leitor é responsável pela identificação de cada elemento constitutivo do texto, iniciando pelas menores unidades até chegar às maiores construções, ou seja, passando dos fonemas aos grafemas, palavras, frases, enfim, estabelecendo uma extração sucessiva de significados das menores às maiores unidades, seguindo uma ordem crescente.

Para a abordagem projetada pelo modelo ascendente, privilegiada pela Linguística Estruturalista, "[...] a leitura é um processo linear que se desenvolve palavra por palavra. Deste dimensionamento, o significado é extraído - vai-se acumulando - à medida que as palavras vão sendo processadas" (LEFFA, 1996, p.12). Fica evidente que o modelo estabelece um conceito de leitura que privilegia a decodificação de unidades como movimento capaz de levar o leitor a decodificar num processo crescente, com base na junção de elementos menores. Nesse modelo, a compreensão decorre de um processo inconsciente e automático, ou seja, o leitor estabelece as relações necessárias entre as unidades da língua, decodificando o código por meio de operações cognitivas que, segundo Kleiman (1999), “[...] regem os comportamentos automáticos, inconscien- 
tes do leitor, e o seu conjunto serve essencialmente para construir a coerência local do texto, isto é, aquelas relações coesivas que se estabelecem entre elementos sucessivos, sequenciais no texto" (KLEIMAN, 1999, p. 50).

Com base nos direcionamentos apontados, a caracterização do leitor cuja ação leitora é baseada unicamente no método bottom-up é aquela que embasa toda a compreensão unicamente nos dados do texto e, dessa forma, não leva em consideração os implícitos e, tampouco, atenta para a recuperação dos conhecimentos prévios para estabelecer a construção dos sentidos (KATO, 2007, p. 50). Olhando para os estudos do ponto de vista do processamento textual, percebemos que corroboram o método bottom-up, que parte de uma concepção de língua como código, ou seja, pauta-se como "mero instrumento de comunicação" (KOCH; ELIAS, 2011, p. 16). Assim, uma vez que o foco reside no texto e a língua é concebida como código, como estrutura, o sujeito é caracterizado como "assujeitado", cabendo-lhe o papel de decodificador sendo, pois, essencialmente passivo (KOCH; ELIAS, 2011).

No campo pedagógico, essa concepção de leitura fundamentou os chamados métodos sintéticos de alfabetização descritos por Frade (2005) como aqueles cuja dinâmica do ensino vai das partes para o todo, criticado por Braggio (1992) ao discutir que o método fônico representa um pressuposto que embasa a prática docente e a construção de materiais didáticos que, por sua vez, representam instrumentos promotores de prejuízos ao processo educativo e à inserção do indivíduo comunicativo no mundo em que ele vive (BRAGGIO, 1992). Percebe-se, pela crítica apresentada por Braggio (1992), tratar-se de uma visão por meio da qual o ato de ler restringe-se à apreensão de traços segmentados, deixando fora do foco de atenção a compreensão dos sentidos emanados do texto.

É importante destacar a existência de muitos questionamentos relacionados ao processo de leitura fundamentado na decodificação. Teóricos como Galveias (2005), Solé (1998; 2012 ), Koch (2011), Marcuschi (2011), Bortoni-Ricardo (2012), entre outros, ratificam que a decodificação corresponde a uma condição fundamental para o leitor, de modo que, se ela não for satisfatoriamente atendida, não será possível migrar a outros níveis do processo de ler. Por outro lado, apenas a decodificação não atinge sozinha as necessidades para uma leitura eficaz. Sob um olhar inverso, o modelo descendente, simultâneo, ou top-down, é teoricamente defendido por Smith (1999), Charmeux (1975) e Goodman (1967), autores que propõem um modelo de leitura de base psicolinguística. Encontram suas bases teóricas no gerativismo-transformacional de Chomsky (1965), fundamentando-se na visão inatista que, segundo Braggio (1992), defende que, assim como as crianças aprendem a falar por uma capacidade inconsciente de entender a língua, a leitura também corresponderia a um ato puramente mecânico. Por essa dimensão, a leitura ocorre com base numa abordagem não linear, guiada por direcionamentos intensivos e dedutivos de informações não visuais. Assim, ocorre um momento em que se parte do macro para a microestrutura, como também da função para a forma (Kato, 2007, p. 50).

Trata-se de uma leitura de base processual e hierárquica, porém num movimento contrário ao ascendente. Agora, o leitor parte dessas hipóteses e antecipações antes de proceder à leitura do código, que servirá como instrumento para verificação de suas 
previsões iniciais, ou seja, "A leitura é vista como atribuição de sentido ao texto, mediante um processo de formulação de hipóteses e antecipações, no qual também intervêm as intenções do leitor que o conduzem a realizar a leitura" (MICOTTI, 2012, p. 13). Caracteriza-se, dessa maneira, como um processo de compreensão global, abrangente, facilmente marcado e direcionado por aspectos emocionais, sociais, intelectuais, entre outros. Os elementos do contexto desempenham primordial papel na compreensão do leitor, mesmo que, em alguns casos, tais hipóteses não encontrem no texto elementos plausíveis à confirmação.

Com base no movimento proposto nesse modelo, o leitor é caracterizado como aquele que apresenta facilidade para apreender as ideias gerais do texto e, com isso, é fluente e veloz. Peca, todavia, pelo excesso de adivinhações fundamentadas em elementos do contexto, muitas vezes sem confirmação nos dados do texto, ou seja, sua compreensão está pautada em dados oriundos de seus conhecimentos prévios, em detrimento da informação apresentada no texto (KATO, 2007). No processamento descendente, diferentemente do ascendente, o estímulo visual consiste apenas em um gatilho dos chamados Esquemas que, segundo Kato (2007, p. 52), "são pacotes de conhecimentos estruturados, acompanhados de instruções para seu uso", ou seja, "A possibilidade de leitura descendente está, pois, diretamente ligada à familiaridade, isto é, à presença ou não da palavra em nosso léxico mental" (KATO, 2007, p. 53).

No campo pedagógico, essa concepção de leitura fundamentou os chamados métodos analíticos de alfabetização descritos por Frade (2005) como aqueles cuja dinâmica do ensino vai do todo para as partes. Sob esse prisma, a leitura configura-se como um processo mediante o qual ocorre captação de ideias do autor pelo leitor por meio de previsões lógicas. Vale salientar que nem todas as previsões realizadas pelo leitor são aceitas, visto que essas estão limitadas à captação das intenções do produtor do texto, aspecto pelo qual aproximamos a visão descendente à concepção de leitura com foco no autor.

Pelo olhar do processamento textual, segundo Koch e Elias (2011), a leitura deve ser entendida como uma ação de "captação de ideias do autor" sem que sejam levados em conta aspectos referentes aos conhecimentos de mundo e experiências do leitor, visto que o que deve ser considerado, sob esse olhar, são as intenções do autor, cabendo ao leitor apenas percebê-las por meio de um jogo linguístico de confirmação de expectativas e de hipóteses. Considerando o modelo ascendente e o processamento textual com foco no texto, Kleiman (2011) destaca como aspectos positivos dessa visão o fato de se caracterizar como um modelo cuja especificidade traz como vantagem a possibilidade de testagem das "predições", visto que "[...] na investigação empírica fazem sentido tarefas de latência e de reconhecimento de letras, sílabas e palavras, e até sentenças isoladas, que não são tarefas de leitura propriamente ditas, e, portanto, têm escassa pertinência às questões aplicadas" (KLEIMAN, 2011, p. 32).

As críticas apresentadas por Kleiman (2011) vão ao encontro daquelas que embasam a construção de modelos didáticos voltados à destituição do leitor passivo, preso unicamente às amarras da superfície do texto, mas não excluem a importância dos elementos lexicais para a compreensão. Refletindo, sob esse prisma, surge a terceira abordagem por meio da qual ocorre a visualização acerca da necessidade de integração das 
abordagens ascendente e descendente e, por tal medida, nem se centra inteiramente nos aspectos textuais, tampouco somente nos aspectos contextuais, constituindo uma concepção interativa, fundamentando-se em um jogo cognitivo e linguístico que permite ao leitor o translado entre os níveis do texto por meio da inferenciação.

Kleiman (2011) busca em Kintsch (1978) e Adamns e Collins (1979) as bases, na Psicologia da Educação, para explicar que a interação a que se refere esta discussão não diz respeito àquela que se dá entre o leitor, sob a determinação de um contexto, tampouco do ponto de vista do autor, definido pelo texto, mas que essa interação de que se fala diz respeito ao "inter-relacionamento" entre esses dois níveis, de modo que não há hierarquia designatória de valor entre os processos, mas uma simultaneidade necessária à proposição de uma leitura eficaz, ou seja, "[...] nos modelos interativos, ambos os tipos de processamento se inter-relacionam no processo de acesso ao sentido" (KLEIMAN, 2011, p. 31), não havendo um pré-requisito de linearidade.

Solé (1998, p. 24) ressalta que é possível afirmar que o modelo interativo designa ser o processo de leitura deveras complexo e, para que tal processo seja efetivado, é imprescindível que o leitor domine habilidades de decodificação além de estratégias mobilizadoras de conhecimentos contextuais que o levem à compreensão. Esse leitor, considerado maduro ou competente, caracteriza-se como aquele cuja ação, posto que é ativo, é fundamentada no uso dos modelos ascendente e descendente no momento mais adequado à leitura, ou seja, tem competência para fazer uso dos dois processos simultaneamente. Assim, "[...] é o leitor para quem a escolha desses processos é já uma estratégia metacognitiva, isto é, é o leitor que tem um controle consciente e ativo de seu comportamento" (KATO, 2007, p. 51).

Pautando-se na visão de Kleiman (2011, p. 38), percebe-se que, numa perspectiva da Psicologia da Educação, "[...] a leitura é um processo interativo porque o 'desvendamento' do texto se dá simultaneamente através da percepção de diversos níveis ou fontes de informação que interagem entre si". Nesse modelo, proposto como uma alternativa para os modelos unidirecionais de processamento - descendente e ascendente - cada nível do conhecimento representa um aspecto capaz de direcionar ou de impedir uma análise por parte do leitor. A interação desses processos é desencadeada por uma série sucessiva de ações realizadas pelo leitor durante a inter-relação das fontes de conhecimento no nível do texto, seja explícito ou implícito, com seus conhecimentos prévios e, a partir dessa interação é que se dá a visualização das leituras autorizadas para cada contexto. Nessa dimensão, interagem aspectos cognitivos, linguísticos e socioculturais. A capacidade de eleger entre essas possíveis leituras aquela que melhor se adéqua à condição na qual se encontra o leitor representa uma marcação de desenvolvimento de sua capacidade de leitura, ou seja, de que é capaz de percorrer os caminhos da leitura de forma consciente e fazer uso de estratégias que a efetivem.

Estabelecendo os laços teóricos, podemos afirmar que se constitui um leitor ativo aquele que se mostra capaz de desencadear os entrelaçamentos necessários à construção dos sentidos, pautando-se nos aspectos do texto, nas pistas textuais marcadas no léxico, nas intenções do autor e nos conhecimentos de mundo. Essa construção requer, todavia, conforme já estabelecido, a capacidade de guiar os próprios caminhos leitores 
, de desenvolver uma consciência linguística para perceber os indícios, os padrões, as marcas, enfim, os elementos marcados no texto que impossibilitam que se faça qualquer leitura, como também para que caminhos no mundo apontam estes indícios.

São essas amarrações a serem feitas pelo leitor durante o processo construtivo que resultam na execução de ações promotoras de uma leitura. Tais ações partem da decodificação necessária, uma vez que um dos elementos constitutivos do texto é o código linguístico. A ação do leitor, no entanto, não para nesse nível, mas interage com os demais aspectos, ou seja, levanta hipóteses, refuta-as ou comprova-as com base nos indícios inscritos no léxico, nos conhecimentos de mundo, em aspectos de referenciação, até chegar à compreensão, efetivando o processo de leitura. No campo pedagógico, essa concepção de leitura fundamentou os chamados métodos mistos de alfabetização descritos por Frade (2005) como aqueles que consideram a simultaneidade dos movimentos, tanto do todo para as partes como das partes para o texto, ou seja, num olhar ascendente ou descendente.

Situamos nossa pesquisa num entrecruzamento de áreas teóricas preocupadas com o processo de leitura, desde a Psicologia Educacional, a Psicolinguística, a Linguística Textual, a Linguística Cognitiva, a Psicologia Cognitiva, numa visão de leitura de base sociointerativa e, nesse contexto, passaremos a discutir e delimitar qual é a percepção de leitor competente, para a qual será necessário revisitar conceitos situados na intersecção dos estudos linguísticos e pedagógicos, ou seja, é preciso definir habilidades e competências para entender esse leitor competente, como também quais os aspectos voltados ao seu desenvolvimento como leitor.

\section{COMPETÊNCIAS E HABILIDADES: Existem Caminhos Para um Leitor Competente?}

Sendo a leitura um ato complexo de produção de sentidos e considerando que o leitor é capaz de estabelecer as relações necessárias para compreender o texto que se propôs a ler, "Compreender não é uma ação apenas linguística ou cognitiva. É muito mais uma forma de inserção no mundo e um modo de agir sobre o mundo na relação com o outro dentro de uma cultura e uma sociedade" (MARCUSCHI, 2011, p. 89). Ser capaz de estabelecer as relações necessárias diz respeito a desenvolver determinadas habilidades, sejam elas no nível consciente ou inconsciente, ou seja, cognitivo ou metacognitivo. Assim sendo o leitor, para ser capaz de reconstruir os sentidos do texto, necessita mobilizar uma série de processos ou habilidades para se tornar competente, ou seja, "[...] se ensinarmos um aluno a ler compreensivamente e a aprender a partir da leitura, estamos fazendo com que ele aprenda a aprender, isto é, com que ele possa aprender de forma autônoma em uma multiplicidade de situações" (SOLÉ, 1998, p. 47).

Para estabelecer a delimitação do que entendemos por leitor competente, partimos da definição de Perrenoud (1999, p. 7), que estabelece competência como "[...] a capacidade de agir eficazmente, em um determinado tipo de situação, apoiada em conhecimentos, mas sem limitar-se a eles". A definição apresentada por Perrenoud (1999) deixa evidente que a competência corresponde a modalidades estruturais da inteligência cujo aprendizado, por não ser inato, ocorre com base em situações que direcionam o indivíduo à construção, mobilização, utilização e integração de conhecimentos diversos. 
Saber ler é, pois, uma competência requerida a todo usuário da língua, inserido em uma sociedade letrada e, dessa forma, todas as ações por ele realizadas visando à compreensão do texto lido, independentemente do gênero, são consideradas, neste estudo, como habilidades, ou seja, o saber fazer, procedimentos esses que podem ser desenvolvidos mediante estratégias de ensino de leitura. Kleiman (1999) e Solé (1998) definem que a compreensão de um texto envolve, por parte do leitor, a execução de processos cognitivos. ${ }^{3} \mathrm{Na}$ visão das autoras, esses processos podem ser puramente cognitivos, ou seja, automáticos, inconscientes e, como tal, não podem ser monitorados ou controlados, mas podem ser estimulados. É preciso ainda, no entanto, olhar para algumas dessas capacidades como situações controladas pelo leitor por intermédio de estratégias metacognitivas. Kato (2007) destaca a existência de dois grupos de estratégias: as cognitivas e as metacognitivas. Segundo a autora, as estratégias cognitivas, especificamente na área de discussão da leitura, designam "[...] os princípios que regem o comportamento automático e inconsciente do leitor" (p. 144). Já as estratégias metacognitivas em leitura consistem em "[...] princípios que regulam a desautomatização consciente das estratégias cognitivas" (p. 144), ou seja, poderiam ser definidas como o domínio de estratégias pelas quais o leitor é consciente de seus percursos e sabe, necessariamente, os caminhos que o levarão à compreensão, como também quando essa não se efetiva .

Estabelecendo relação mais específica entre os aspectos teóricos tratados, com base em Poersch (1998) e Marcuschi (2011), o que é designado como competência e habilidade está relacionado "ao saber e ao saber fazer", ou seja, aos mecanismos de acesso à informação, às relações estabelecidas entre elas, à definição de objetivos, enfim, às diversas operações realizadas pelo leitor para mobilizar os conhecimentos presentes no texto, no mundo e em seu repertório prévio de modo a construir a compreensão. Já as estratégias estão relacionadas às situações conscientes por meio das quais é possível estimular ou desenvolver habilidades de leitura. Acrescentando a essa discussão, Flores e Gabriel (2012) estabelecem os enlaces entre a Linguística Textual em Koch (2002) e Antunes (2005), a Teoria da Enunciação em Benveniste $(1995,1989)$ e Fiorin (1999), a Semântica Argumentativa em Ducrot (1998, 1981), a Teoria dos Atos de Fala em Austin (1990) e a Análise Textual do Discurso em Adam (2008), evidenciando que essas teorias compreendem que, no processo de textualização,

[...] o autor do texto se propõe a dizer algo, quando escreve, por isso deixa marcas, os rastros orientadores da leitura do texto produzido. Essas marcas podem ou não ser apreendidas pelo leitor, no entanto, estão lá, explícitas ou implícitas; claras, confusas ou difusas, bem ou mal sugeridas pelo seu produtor (FLORES; GABRIEL, 2012, p. 222).

\footnotetext{
Segundo Vasconcelos e Dionísio (2013, p. 48), "A cognição humana compreende os processos e produtos mentais (consciência, inteligência, pensamento, imaginação, criatividade, elaboração de planos e estratégias, resolução de problemas, inferência, conceitualização e simbolização, etc.), por meio dos quais percebemos, conhecemos, concebemos e transformamos o mundo".
} 
Diante dessa explicação, o leitor competente é aquele que mobiliza habilidades necessárias para mergulhar em diversos níveis do texto e, para isso, reconhece nas marcas textuais as pistas para que traga de seus conhecimentos previamente construídos na sociedade, na cultura e em outras leituras, as informações necessárias para preencher as lacunas existentes no texto de modo a compreendê-lo, como ato colaborativo entre autor-texto e leitor, a fim de construir os sentidos aceitáveis, visto que o texto não é um objeto aberto a qualquer interpretação.

Do ponto de vista do ensino, assume-se uma posição pela qual o professor figura como mediador de um processo psicolinguístico, fundamentado numa concepção de leitura como interação e, daí, considerando desde a decodificação até os conhecimentos prévios e de mundo mobilizados pelo leitor. Nesses termos, a criação de situações por meio das quais o aluno é desafiado a realizar operações como observar, analisar, relacionar, concluir e comparar, entre outras, diante de textos de naturezas diversas, tanto na intencionalidade quanto em sua constituição em níveis de conhecimentos diversos, como também de linguagem, representa a possibilidade de o aluno compreender como se dão os mecanismos constitutivos dos textos. Esses procedimentos ou estratégias de leitura são também mencionados por Solé (1998), e por Kleiman (1999) como estratégias cognitivas e metacognitivas.

A metacognição ou metacompreensão, definidas por Bolivar (2002), refere-se, enfim, à capacidade do leitor em estabelecer as relações necessárias para conectar os diferentes conhecimentos que se entrelaçam em um texto, visto que muito está no nível explícito, mas grande parte encontra-se no implícito ou apenas são pistas para que se volte aos conhecimentos prévios ou ao contexto. Assim, de modo geral, Galveias (2005, p. 698) explica que todas as estratégias são guiadas por algumas outras consideradas básicas. Configuram estratégias básicas a capacidade de: tolerar a indecisão e contornar uma dificuldade; reconhecer rapidamente uma palavra, uma frase, perceber um grupo de palavras; formular hipóteses; utilizar os seus conhecimentos referenciais e conhecimentos textuais; fazer inferências. Nessas estratégias previamente apresentadas observa-se uma expansão do que a concepção de leitura adotada já estabelece, ou seja, uma leitura que foque nos aspectos geradores de informação, isto é, nos elementos inscritos no texto, na formulação e refutação de hipóteses e na contribuição contextual na construção destas duas dimensões.

Macedo (2008), no entanto, alerta para o fato de que dispor de certas habilidades não é suficiente, por si, para gerar um ser competente, visto que "[...] para ser competente, devemos ser habilidosos, mas ser habilidoso nem sempre é suficiente para ser competente. Em outras palavras, habilidade faz parte de competência, mas esta exige muitos outros aspectos além daquela" (MACEDO, 2008). Na visão de Macedo (2009), o desenvolvimento de habilidades e competências de leitura e escrita gera, ainda, a capacidade leitora que, por sua vez, “[...] dentro do processo de aprendizagem e domínio da língua materna, de acordo com a proposta da teoria dos gêneros textuais, capacidades de linguagem" (FRANÇA, 2010).

Cientes dos aspectos envolvidos na compreensão, passaremos a analisar quais são os conhecimentos constitutivos dos textos e como se dá a relação de mobilização desses com base nos procedimentos aqui referenciados como habilidades/estratégias 
de leitura, estabelecendo um recorte do papel do léxico nesta rede construtiva. Numa concepção construtivista de ensino, fundamentada em bases psicolinguísticas e, portanto, numa concepção sociointerativa de leitura, o desenvolvimento da leitura só é possível com base em uma construção conjunta na qual o aluno/leitor passa a se apropriar de conhecimentos e procedimentos ao passo que os vai compreendendo, imerso no processo. Não se trata, porém, de uma situação somente de contato com os textos, como se a aprendizagem desses comportamentos linguísticos ocorresse como que por "osmose", mas da apropriação a partir da interação, colocando-se as habilidades metacognitivas, ou de metacompreensão, a serviço da metalinguagem.

Em meio à complexidade desse processo, repousa a condição do leitor de estabelecer estratégias para dar respostas às expectativas geradas, confirmando e refutando hipóteses. Assim, a cada nova leitura, o leitor vai se apropriando de situações que o levam a construir padrões significativos que, em novas situações de leitura, não mais representarão expectativas, levando-o sempre um nível à frente. Ainda sobre esse complexo olhar sobre a leitura, retomando as concepções já abordadas, é unânime entre os teóricos voltados à discussão a importância de um olhar equitativo sobre os aspectos constitutivos dos textos, ou seja, é preciso que o leitor tenha certo domínio sobre dimensões que são primordiais à construção dos sentidos. A esse respeito, Sim-Sim (2007) assevera que

[...] de realçar o conhecimento linguístico, particularmente a riqueza lexical e o domínio das estruturas sintácticas complexas, a rapidez e a eficácia com que identificam palavras escritas, a capacidade para automatizar a compreensão, o conhecimento que têm sobre o mundo e sobre a vida e, muito particularmente, sobre os assuntos abordados nos textos lidos (p. 22).

Assim, ao mesmo tempo em que se estabelecem hipóteses levando em conta os aspectos visuais do texto e os conhecimentos prévios do leitor, é preciso buscar nas marcas textuais as respostas para hipóteses formuladas. Dessa reflexão, passemos a analisar, então, os pilares constitutivos da compreensão leitora por meio da percepção do lugar das relações lexicais no desenvolvimento de estratégias e sua contribuição para a competência leitora.

\section{O LUGAR DO LÉXICO NO DESENVOLVIMENTO DE ESTRATÉGIAS PARA CONSTRUÇÃO DA COMPETÊNCIA LEITORA: Desenvolvendo Habilidades}

Visando a analisar o lugar do léxico no desenvolvimento das estratégias de leitura e, consequentemente, a contribuição à competência leitora, tomamos como base o ensino da Língua Portuguesa e seus direcionamentos na sala de aula, sob os quais discutiremos o papel compreensivo da leitura, tendo como escopo a Matriz de Língua Portuguesa desenvolvida pelo Sistema Nacional de Avaliação da Educação Básica - Saeb. Para melhor compreender como estão organizadas as Matrizes, retomamos França (2013), que explica o fato de que os descritores, tal como são apresentados na Matriz de Referência de Língua Portuguesa, consistem em uma associação entre conteúdos curriculares e operações mentais a serem produzidas pelo aluno, cujo desenvolvimento traduz competências e habilidades mobilizadas pelos discentes. Assim, cada descritor corres- 
ponde a habilidades que se espera dos alunos, ou seja, são as ações que os leitores devem saber fazer e, por sua vez, necessárias à construção da compreensão durante a realização desses exames.

Assim, se "[...] os descritores indicam habilidades gerais que se espera dos alunos e constituem a referência para seleção dos itens que devem compor uma prova de avaliação" (FRANÇA, 2013, p. 288), a nosso ver, as habilidades delimitadas em cada descritor devem também ser apreciadas no momento da construção de ações de ensino, pois somente se pode avaliar aquilo que, de uma maneira ou de outra, foi desenvolvido. Sustentamos ainda que, para serem desenvolvidas, é necessário estímulo, o que aqui entendemos como ações de ensino e aprendizagem, estratégias definidas. Ratificando o propósito inicialmente apresentado, ou seja, analisar o lugar do léxico no desenvolvimento das estratégias de leitura e, consequentemente, a contribuição ao desenvolvimento de habilidades e dessas à competência leitora, passaremos a visualizar, de forma mais precisa, esses aspectos em cada um dos tópicos constitutivos da Matriz Curricular de Língua Portuguesa, que está baseada em duas dimensões: objeto do conhecimento e competência.

O objeto do conhecimento contemplado na Matriz é apresentado por meio de sete tópicos, ou seja, procedimento de leitura, implicações do suporte, do gênero e/ou do enunciador na compreensão do texto, relação entre textos, coerência e coesão no processamento do texto, relações entre recursos expressivos e efeitos de sentido e variação linguística. Já a competência leitora, de acordo com França (2013), é construída pelas habilidades definidas em cada um dos descritores que indicam o saber fazer determinadas ações a serem avaliadas em cada tópico. Há a indicação de três matrizes nas quais são contemplados os descritores de acordo com os níveis de ensino. Com base nessa estrutura, passaremos a analisar cada um desses tópicos, estabelecendo a ênfase na relação entre competência, habilidade, estratégias e relações lexicais, análise para a qual assumimos uma concepção de léxico como

[...] o conjunto de palavras que pode ser verificado nos enunciados dessa língua ou representado nos dicionários. Do ponto de vista interno, ou mental, o léxico corresponde não apenas às palavras que um falante conhece, mas também ao conhecimento de padrões gerais de estruturação, que permitem a interpretação ou produção de novas formas (BASílIO, 2011, p. 12-13).

Dessa maneira, o léxico constitui, segundo Marcurschi (2004), um dos pilares da língua ao lado da sintaxe e da fonologia, mas, diferentemente dessas que apresentam um conjunto mais regular de possibilidades, o léxico caracteriza-se pela instabilidade criativa e a mutabilidade da língua, aspectos considerados intrínsecos à cognição e ao discurso. Na visão de Antunes (2007), o léxico consiste em um "[...] depositário dos recortes com que cada comunidade vê o mundo, as coisas que a cerca, o sentido de tudo". Sob esse prisma, a autora reforça a função do léxico, destacando as palavras como unidades de sentido que funcionam como verdadeiras peças de um jogo, de uma teia de significados do texto, e destaca, ainda, que "Como unidades de sentido, ainda, funcionam como elos de amarração de subpartes do texto. São unidades dos nexos com que se constrói a cadeia do texto" (ANTUNES, 2007, p. 43). 
Ademais, retomada a reflexão acerca do léxico, aspecto no qual reside nossa delimitação de estudo, Sim-Sim (2002) defende que o processo de leitura deve ser pensado em sua continuidade, visto que consiste no momento no qual o leitor vai agregando em seu repertório novas palavras, construções sintáticas, enfim, novos comportamentos da língua que se somam aos já construídos, continuadamente. Kato (2007) explica que nesse processo o leitor vai construindo uma memória, uma representação mental consciente mediante a qual as informações são percebidas e internalizadas e, como já compreendidas, possibilitam a integração de novas informações obtidas por meio do texto.

O Tópico 1, que trata do objeto do conhecimento definido como os "procedimentos de leitura", contempla os seguintes descritores: as habilidades de localizar informações explícitas em um texto; inferir o sentido de uma palavra ou expressão; inferir uma informação implícita em um texto; identificar o tema de um texto; distinguir um fato da opinião relativa a esse fato. Ao observarmos esse tópico, percebemos que cada descritor é introduzido por uma "ação a saber fazer", ou seja, LOCALIZAR, INFERIR, IDENTIFICAR, DISTINGUIR. Dessa forma, cada descritor estabelece uma ligação entre um saber fazer (habilidade) com um nível de conhecimento, concomitantemente, INFORMAÇÕES, SENTIDO, PALAVRA, EXPRESSÃO, TEMA, FATO, OPINIÃO que, por sua vez, são acionados por elementos inscritos no léxico. Trata-se, pois, de ações que podem ser aprendidas por meio da mediação e, como tal, mediante estratégias de leitura de natureza metacognitiva.

Considerando o aspecto consciente das atividades metacognitivas de leitura, tomamos como base o D1 - Localizar informações explícitas em um texto e questionamos até que ponto o leitor poderá "localizar" essas informações como se elas estivessem prontas e dadas nos textos. Antunes (2012, p. 29) esclarece que "[...] às palavras são associados significados básicos, que constituem, isso mesmo, a base para a derivação de outros significados, próximos, associados, afins". Nesse sentido, para estabelecer a relação entre os significados possíveis, o leitor necessita mergulhar em um jogo de associações entre as bases lexicais que já possui com a percepção dos sentidos possíveis estabelecidos no contexto e, somente por meio dessa relação, perceber qual ou quais dos "significados básicos" foram eleitos naquele momento ou, ainda, se ocorreu a produção de um novo significado. Em outras palavras, as ações mediadas mediante as quais o leitor concebe os percursos a serem seguidos de modo a perceber a consciência do próprio nível de compreensão, durante a leitura, representam o desenvolvimento de ações metacompreensivas.

A complexidade do ato amplia-se a partir das ações relacionadas em D3 - Inferir o sentido de uma palavra ou expressão e D4 - Inferir uma informação implícita em um texto, presente nos três níveis. Sobre esses dois descritores, cabe-nos retomar Marcuschi (2011, p. 94) para melhor compreendermos que "as inferências atuam como hipóteses coesivas para o leitor processar o texto, ou seja, como estratégias ou regras embutidas no processo". Rickheit e Strohner (1993, p. 8) acrescentam que "[...] uma inferência é a geração de informação semântica nova a partir de informação semântica velha num dado contexto", caracterizando o ato de ler como uma atividade de construção de sentidos que, por sua vez, não são aleatórios, visto que nem todas as hipóteses que são construídas durante o processo são aceitas, mas somente aquelas direcionadas 
pelo autor e pelo texto, num determinado contexto. Assim, as inferências realizadas pelo leitor, quanto aos sentidos de palavras ou expressões, são guiadas pelas pistas lexicais que direcionam os caminhos percorridos pelo autor na construção do texto e as informações que podem ser recuperadas no nível do implícito.

A partir dessa visão, apontamos uma questão crucial: é fundamental perceber que todas essas ações remetem à necessidade de perceber a língua em sua instabilidade, tendo em vista que os sentidos são construídos em um contexto. Ao mesmo tempo, também é necessário que o leitor perceba que nem todas as leituras são possíveis e que há, inscritos no texto, sentidos regularizados ou não pelo uso. Sobre as regularidades, Castilho (2010) demonstra cautela ao argumentar que

[...] as palavras e suas propriedades não são apriorísticas, não representam uma espécie de "pacote" que recebemos pronto, assumindo-se, aqui, ao contrário, que esse tipo de conhecimento linguístico é continuadamente refeito nas situações concretas de fala. Nossa atitude em relação à língua é sempre dinâmica e criativa (p. 110).

Tal visão é ratificada ao verificarmos no D6 - Identificar o tema de um texto a necessidade de o leitor estabelecer relações e hipóteses que serão verificadas no próprio texto e que podem ser mais rapidamente visualizadas se o leitor perceber a existência de um campo semântico, marcado nas escolhas lexicais que o determinam.

Nos descritores D11 - Distinguir um fato da opinião relativa a esse fato e D15 Reconhecer diferentes formas de tratar uma informação na comparação de textos que tratam do mesmo tema, em função das condições em que ele foi produzido e daquelas em que será recebido, saber DISTINGUIR fato de opinião pressupõe, inicialmente, RECONHECER, PERCEBER, IDENTIFICAR se em dado texto há marcas que determinam serem as informações mencionadas "fatos" ou "opiniões". Por outro lado, se não forem dadas diretamente como fato ou opinião, requerem do leitor a habilidade de identificar nos marcadores de pressuposição as pistas necessárias ao reconhecimento entre o dado e o implícito, entre o objetivo e o subjetivo, ou seja, entre o fato e a opinião.

Nesse sentido, é preciso fazer do ato de ler uma atividade produtiva de construção e reconstrução de sentidos e, dessa maneira, perceber que ações como LOCALIZAR, INFERIR, IDENTIFICAR, DISTINGUIR são acionadas pelas marcas inscritas no léxico ou nas relações por ele estabelecidas em seu momento de uso, ponderando os direcionamentos necessários para que o leitor construa hipóteses durante a leitura, refute-as ou comprove-as com base em provas cotextuais e contextuais. As marcas lexicais são, portanto, determinantes para o movimento entre o leitor, o texto, as intenções do autor e os conhecimentos de mundo, estabelecendo os sentidos possíveis de serem eleitos em cada situação, pois, como destaca $\operatorname{Sim}-\operatorname{Sim}(2002$, p. 222), no ensino, “[...] ajudar a criança a reflectir sobre a língua é possibilitar-lhe ascender a níveis mais elevados do conhecimento linguístico que, por sua vez, se reflectirá na forma como ela compreenderá o material escrito e a mensagem nele contida".

Dessa forma, ratificamos o papel fundamental dos estudos lexicais visto que, para que seja possível a localização de informações explícitas em um texto, inicialmente é necessário que o leitor recorra ao repertório previamente construído, visto que, confor- 
me assevera Marcuschi (2004), “[...] a questão não é qual o papel do léxico na produção de sentido e sim qual a nossa forma de operar com o léxico para produzir sentido" ( $p$. 270). Essa operacionalização sobre as relações lexicais contribui significativamente para o desenvolvimento de um leitor fluente, visto que, ao mesmo tempo em que constrói bases lexicais prévias, ele migra para novas ações, ou seja, a construção dos sentidos flui de maneira mais rápida, uma vez que já disponibiliza de bases lexicais ou compreende a manifestação dos fenômenos construídos em situações diversas de leituras, posto que, nessa perspectiva, é necessário perceber o léxico "[...] como elemento da composição do texto, em suas funções de criar e sinalizar a expressão dos sentidos e intenções, os nexos de coesão, as pistas da coerência" (ANTUNES, 2012, p. 24).

Quanto aos procedimentos de leitura, as estratégias voltadas à construção dos sentidos, seja por meio de informações explícitas ou implícitas, podem ser impulsionadas por uma dinâmica de leitura mediante a qual o leitor aprenda a reconstruir sentidos, guiado pelas inscrições no léxico, como estratégias de metacompreensão, ou seja, "[...] una estrategia de enseñanza metacognitiva se refiere al conjunto de procedimientos que utiliza el docente no sólo para transmitir un contenido determinado, sino para entrenar al alumno en la autodirección y autorregulación de su propio aprendizaje" (Bolivar, 2002, p. 55). Como já visto, a discussão aqui apresentada é igualmente rica para diversas vertentes científicas. Salientamos, no entanto, que nosso olhar será direcionado aos aspectos do desenvolvimento da leitura do ponto de vista do ensino e com base nas teorias semântico-lexical. É nesse movimento que, a cada nova leitura, o leitor vai se apropriando de elementos que o levam a construir padrões significativos que, em novas situações de leitura, não mais representarão expectativas, levando-o sempre a um nível à frente. Em outras palavras, segundo Schmidt (1978), a partir do momento em que a língua é visualizada em situações de uso, gera condições para que seu usuário perceba padrões e compreenda como a língua funciona. Assim, a compreensão de uma situação leva o leitor a estar apto a compreender outras, visto que cada padrão está ligado a uma situação de produção de sentido.

Dando continuidade ao olhar sobre a importância do léxico em cada uma das ações inseridas nos descritores em pauta, o Tópico 2 trata das "implicações do suporte, do gênero e/ou do enunciador na compreensão do texto". Pelo teor apresentado, demonstra, explicitamente, contemplar os aspectos que contribuem para a percepção das informações a partir de elementos da estrutura e do propósito comunicativo, representados por D5 - Interpretar texto com auxílio de material gráfico diverso (propagandas, quadrinhos, fotos, etc.) e D9 - Identificar a finalidade de textos de diferentes gêneros. Para o Ensino Médio, D9 é ampliado e substituído por D12 - Identificar a finalidade de textos de diferentes gêneros nos níveis correspondentes ao nível final do Ensino Fundamental e do Médio.

Ressaltamos que, diferentemente do senso comum que acredita serem os textos multimodais aqueles que apresentam condições mais amenas e promovem a facilidade de compreensão, ocorre o inverso, haja vista que o leitor deve dispor de habilidades para relacionar diferentes formas de manifestação da linguagem. Além disso, por serem 
textos que em sua grande maioria exigem uma condensação de informações no nível do posto, há uma gama de outras no nível do implícito, sejam por meio de pressupostos ou subentendidos.

A próxima competência é expressa no Tópico 3, que se baseia no saber relacionar textos. São, pois, apresentados os seguintes descritores/habilidades:

Quadro 1 - Descritores da competência 3

D15 - Reconhecer diferentes formas de tratar uma informação na comparação com textos que tratam do mesmo tema, em virtude das condições em que ele foi produzido e daquelas em que será recebido.

D20 - Reconhecer diferentes formas de tratar uma informação na comparação com textos que tratam do mesmo tema, em razão das condições em que ele foi produzido e daquelas em que será recebido.

D21- Reconhecer posições distintas ou mais opiniões relativas ao mesmo fato ou ao mesmo tema.

Fonte: http://portal.inep.gov.br/web/saeb/31.

Pelas ações pleiteadas em cada um dos descritores apresentados no Tópico 3, fica cada vez mais nítido que são apresentados novos desafios para o leitor com base naqueles que, supostamente, já tenha vencido. Assim, saber comparar informações é precedido pelo saber identificar que, por sua vez, recorre ao ato de decodificar, estabelecer relações e compreender o texto em estudo. São etapas que necessitam ser vencidas num processo contínuo e progressivo. É exatamente o que se verifica nos tópicos seguintes. O Tópico 4 contempla a competência por meio da qual o aluno deverá ser capaz de perceber e construir a coerência e coesão no processamento do texto, a qual é construída, segundo os próprios descritores, pela habilidade do leitor em:

Quadro 2 - Descritores da competência 4

D2 - Estabelecer relações entre partes de um texto, identificando repetições ou substituições que contribuem para a continuidade de um texto.

D7 - Identificar a tese de um texto.

D8 - Estabelecer relação entre a tese e os argumentos oferecidos para sustentá-la. D9 - Diferenciar as partes principais das secundárias em um texto.

D10 - Identificar o conflito gerador do enredo e os elementos que constroem a narrativa.

D11 - Estabelecer relação causa/consequência entre partes e elementos do texto.

D15 - Estabelecer relações lógico-discursivas presentes no texto, marcadas por conjunções, advérbios, etc. 
Percebe-se que D2 contempla a percepção e compreensão dos mecanismos de coesão lexical. D7, D8, D9, D10 e D11 referenciam a habilidade do leitor em reconhecer informações que, por sua vez, são marcadas do texto e cujas pistas estão inscritas no léxico. A respeito das relações lógico-discursivas destacadas no D15, Koch (2012) deixa claro que:

Se, porém, é verdade que a coerência não está no texto, é verdade também que ela deve ser construída a partir dele, levando-se em conta os recursos coesivos presentes na superfície textual, que funcionam como pistas ou chaves para orientar o interlocutor na construção do sentido. Para que se estabeleçam as relações adequadas entre tais elementos e o conhecimento de mundo (enciclopédico), o conhecimento socioculturalmente partilhado entre os interlocutores, e as práticas sociais postas em ação no curso da interação, torna-se necessário, na grande maioria dos casos, proceder a um cálculo, recorrendo-se a estratégias interpretativas, como as inferências e outras estratégias de negociação de sentido (p. 53).

A ideia defendida por Koch (2012) é retomada por meio da descrição da competência expressa pelo Tópico 5, que repousa na habilidade de o aluno estabelecer relações entre recursos expressivos e efeitos de sentido. Nesse tópico destacamos os seguintes descritores, visto que são comuns aos níveis finais do Ensino Fundamental II e do Ensino Médio.

\section{Quadro 3 - Descritores da competência 5}

D16 - Identificar efeitos de ironia ou humor em textos variados.

D17 - Reconhecer o efeito de sentido decorrente do uso da pontuação e de outras notações.

D18 - Reconhecer o efeito de sentido decorrente da escolha de uma determinada palavra ou expressão.

D19 - Reconhecer o efeito de sentido decorrente da exploração de recursos ortográficos e/ou morfossintáticos.

Fonte: http://portal.inep.gov.br/web/saeb/31.

Observando o descritor D16, chamamos a atenção para a ênfase estabelecida nos efeitos de humor que, em sua grande maioria, são construídos com base em gatilhos semânticos decorrentes da condição produtiva da língua, por meio de fenômenos como a polissemia, a homonímia e a vagueza. Já D18 enfatiza a construção dos efeitos de sentido com base em palavras ou expressão, aspecto que também dá ênfase à necessidade de percepção consciente dos fenômenos lexicais envolvidos em cada situação de leitura.

Destacamos, no entanto, que é necessário levar o leitor a compreender, pela proposição de ações de ensino, essas manifestações no texto para que possa se apropriar desses mecanismos e passar a visualizá-los de forma consciente, ou seja, metacompreensivamente, pois, segundo Kleiman (1999), 
[...] embora essas atividades de natureza metacognitiva sejam individuais, é possível o adulto propor atividades nas quais a clareza de objetivos, a predição, autoindagação sejam centrais, propiciando assim contextos para o desenvolvimento e aprimoramento de estratégias metacognitivas na leitura (p. 43-44).

Essa visão defendida por Kleiman (1999) vai ao encontro daquelas contempladas por teorias construtivistas, mediante as quais se percebe que, na discussão sobre o ensino de leitura, é consenso o fato de que as estratégias voltadas ao desenvolvimento das habilidades de leitura não podem ser consideradas estáticas. Por outro lado, essas mesmas teorias defendem o fato de que o desenvolvimento de novas competências pelo aluno decorre de um ponto de partida, daquilo de que ele já se apropriou, pois somente com base no que o leitor já é capaz de perceber diante dos diversos textos é que se poderá estabelecer pontes, ajustar ações e expectativas para a promoção de novas conquistas linguísticas, visto que "não devemos esquecer que competência se cria, se constrói" (SOLÉ, 1998, p. 171). Ratificamos que a construção dessa competência deve ser promovida com base nos pilares do conhecimento linguístico e de mundo, ou seja, nesse processo não se pode dar ênfase a um nível do conhecimento em detrimento do outro.

O último descritor é contemplado na competência 6, ou seja, pela visão acerca da variação linguística, representada pelo D13 - Identificar as marcas linguísticas que evidenciam o locutor e o interlocutor de um texto. Fica evidente em D13 a necessidade de estabelecer metas por meio das quais os alunos percebam que no texto há "marcas linguísticas" e "identificar" consiste no caminho pelo qual esse leitor perceberá outros aspectos, embora igualmente importantes para a compreensão, que antecedem a percepção de elementos do discurso, como o locutor e o interlocutor de um texto. Não se trata de dar ênfase somente às marcas ou às pistas, mas percebê-las como elementos direcionadores do processo de construção dos sentidos emanados do texto e de todos os demais aspectos que dele fazem parte.

\section{CONSIDERAÇÕES FINAIS}

Considerando todas as observações apontadas, percebemos a necessidade de um maior aprofundamento sobre como a interação com os fenômenos lexicais pode configurar a construção de uma nova categoria de estratégias metacompreensivas voltadas ao desenvolvimento da competência leitora. No processo, o leitor ver-se-á diante de uma atividade extremamente complexa para a qual necessita de pistas que, por sua vez, estarão inscritas no léxico, nesse repertório que vem construindo no decorrer de suas experiências linguísticas. Ademais, também encontrará situações nas quais os sentidos previamente vivenciados tomarão outros rumos e, dessa maneira, novos sentidos serão construídos e agregados a seu repertório, devido à condição propriamente ambígua e produtiva que tem a língua.

Sendo atendidos os objetivos deste estudo, por tratar-se de recorte de tese de Doutoramento, ficam evidentes os direcionamentos estabelecidos pelos descritores para a importância do léxico na construção de padrões de leitura, levando o docente a buscar meios de interação entre o leitor e o léxico por intermédio dos textos diversos. Levar o aluno a compreender os comportamentos estabelecidos pelas relações lexicais 
em cada momento do ato de ler é, acima de tudo, disponibilizar de meios necessários para o desenvolvimento de uma leitura autônoma. Assim, transcender a percepção do léxico como meros grafismos e a leitura como uma atividade de adivinhação consiste em um imenso avanço na construção de paradigmas de ensino mais efetivos e comprometidos com a autonomia do leitor.

\section{REFERÊNCIAS}

ANTUNES, Irandé. Língua, texto e ensino: outra escola possível. São Paulo: Parábola Editorial, 2009.

ANTUNES, Irandé. Território das palavras: estudo do léxico em sala de aula. São Paulo: Parábola, 2012.

ANTUNES, Irandé. Muito além da gramática: por um ensino sem pedras no caminho. São Paulo: Parábola Editorial, 2007.

BASILIO, Margarida. Formação e classes de palavras no português do Brasil. 3. ed. São Paulo: Contexto, 2011.

BOLIVAR, Ruiz Carlos. Mediación de Estrategias Metacognitivas en Tareas Divergentes y Transferencia Recíproca. Investigación y Postgrado. Caracas, v. 17, n. 2, p. 53-82, oct. 2002. Disponível em: http://www. scielo.org.ve/scielo.php?script=sci_arttext\&pid=S1316-0087200200020 0003\&lng=es\&nrm=iso. Acesso em: 10 fev. 2017.

BORTONI-RICARDO, Stella Maris. Leitura e Mediação Pedagógica [Org.] [et.al.] São Paulo: Parábola, 2012. BRAGGIO, Sílvia Lúcia Bigonjal. Leitura e alfabetização: da concepção mecanicista à sociolingüística. Porto Alegre: Artes Médicas, 1992.

BRANDÃO, Ana Carolina Perrusi. O ensino da compreensão e a formação do leitor: explorando as estratégias de leitura. In: BARBOSA, Maria Lúcia Ferreira de Figueiredo (org.). Práticas de leitura no ensino fundamental. Belo Horizonte: Autêntica, 2006.

BRASIL. Lei de Diretrizes e Bases da Educação Nacional. Lei no 9.394, de 20 de dezembro de 1996. Brasília: MEC; SEF, 1996.

BRASIL. Secretaria de Educação Básica. Parâmetros Curriculares Nacionais para o Ensino Médio: linguagens, códigos e suas tecnologias. Brasília: MEC; SEF, 2000.

CAMPS, Teresa; COLOMER, Anna. Ensinar a ler, ensinar a compreender. Porto Alegre: Artmed, 2002.

CASTILHO, Ataliba T. de. Nova gramática do português brasileiro. São Paulo: Editora Contexto, 2010.

CHARMEUX, E. La lecture à l'école. Paris: Cedic, 1975.

CHOMSKY, N. Aspects of the Theory of Syntax. Cambridge, MA: MIT Press, 1965.

CORACINI, M. J. R. F. Leitura: decodificação, processo discursivo? In: CORACINI, M. J. R. F (org.). O jogo discursivo na aula de leitura: língua materna e língua estrangeira. Campinas: Pontes, 2002.

COSCARELLI, C. V. Reflexões sobre as inferências. CONGRESSO BRASILEIRO DE LINGUÍSTICA APLICADA CBLA, 6., 2002. Belo Horizonte. Anais [...]. Faculdade de Letras da UFMG, Belo Horizonte, 2002. CD-ROM. DE BORTOLLI, Lúcia Helena. Leitura: os meios da compreensão. Passo Fundo: UPF, 2002.

FLORES, Onici Claro; GABRIEL, Rosângela. O quebra-cabeça da leitura: leitor, texto, autor. In: MOURA, Heronides; GABRIEL, Rosângela (org.). Cognição na linguagem. Florianópolis: Insular, 2012.

FRADE, Isabel Cristina Alves da Silva. Métodos e didáticas de alfabetização: história, características e modos de fazer de professores: caderno do professor. Belo Horizonte: Ceale/FaE/UFMG, 2005.

FRANÇA, José Marcos de. Desenvolvendo habilidades e competências no processo de leitura-escrita: gêneros textuais e artes. In: Interdisciplinar, Itabaiana, SE, a. VIII, v. 19, n. 2, p. 277-294, jul./dez. 2013.

FRANÇA, J. M. . A Didatização de um Gênero do Argumentar: a Carta do Leitor. Interdisciplinar, v. 12, p. 151-166, 2010.

GALVEIAS, M. Aprender a ler, ensinar a compreender: as práticas escolares e a formação de leitores literatos. In: SILVA, B. D.; ALMEIDA, L. S. (coord.). CONGRESSO GALAICO-PORTUGUÊS DE PSICOPEDAGOGIA, 8., 2005. Minho. Actas [...]. Minho, Portugal: Universidade do Minho; Instituto de Educação e Psicologia, 2005. p. 693-708.

GERALDI, João Wanderley. Portos de passagem. 4. ed. São Paulo: Martins Fontes, 1997. (Texto e linguagem).

GOODMAN, K. The psycholinguistic nature of the reading process. Detroit: Wayre State University Press, 1967. 
GOUGH, P. B. One second of reading. In: KAVANAGH, J.F. \& MATTINGLY, I.G.(orgs). Language by ear and by eye. Cambridge: MIT Press,1972, p.353-378).

KATO, Mary. O aprendizado da leitura. 6. ed. São Paulo: Martins Fontes, 2007.

KLEIMAN, Ângela. Leitura: ensino e pesquisa. 4. ed. São Paulo: Pontes Editores, 2011.

KLEIMAN, Ângela. Texto e leitor: aspectos cognitivos da leitura. 6. ed. Campinas, SP: Pontes, 1999.

$\mathrm{KOCH}$, Ingedore Villaça; ELIAS, Vanda Maria. Ler e compreender: os sentidos do texto. 5. ed. São Paulo: Contexto, 2011.

KOCH, Ingedore Villaça. O texto e a construção dos sentidos. 10. ed. São Paulo: Contexto, 2012.

KOLERS, P. A. Memorial consequences of automatized encoding. Journal of Experimental Psychology: Human Learning and Memory, 1(6), 689-701, 1975. https://doi.org/10.1037/0278-7393.1.6.689.

LEFFA, Vilson J. Aspectos da leitura. Porto Alegre: Sagra: DC Luzzatto, 1996.

LEFFA, Vilson. Pesquisa em linguística aplicada: temas e métodos. Pelotas: Educat, 2006.

MACEDO, Lino. Competências na Educação. Instituto de Psicologia da USP 2008. Disponível em http:// www.rededosaber.sp.gov.br/contents/SIGS-CURSO/sigsc/upload/br/site_25/File/competencias_na_educacao.pdf. Acesso em 15/05/2017.

MACEDO, Lino. Competências e habilidades: elementos para uma reflexão pedagógica. In: BRASIL. ENEM: textos teóricos e metodológicos 2009. Brasília: junho de 2009. p. 49-70.

MARCUSCHI, Luiz Antônio. Gêneros Textuais: configuração, dinamicidade e circulação. In: KARWOSKI, Acir Mário; GAYDECZKA, Beatriz; BRITO, Karim S. (Orgs.). Gêneros Textuais: reflexões e ensino. São Paulo: Parábola, 2011.

MARCUSCHI, Luiz Antônio. Compreensão textual como trabalho criativo. Acervo digital Unesp, 2011. Disponível em: http://acervodigital.unesp.br /handle/123456789/40358. Acesso em: mar. 2013.

MARCUSCHI, Luiz Antônio. O léxico: lista, rede ou cognição social? In: NEGRI, Lígia; FOLTRAN, Maria José; OLIVEIRA, Roberta Pires (org.). Sentido e significação: em torno da obra de Rodolfo llari. São Paulo: Editora Contexto, 2004. p. 263-284.

MICOTTI, Maria Cecilia de Oliveira. Alfabetização: propostas e práticas pedagógicas. São Paulo: Contexto, 2012.

ORLANDI, E. P. Discurso e leitura. 9. Ed. São Paulo: Cortez, 2012.

PERRENOUD, Philippe. Construir as competências desde a escola. Porto Alegre: Artmed, 1999.

POLESSI, E.; MENEGASSI, R. J. Proposta de ordenação de perguntas para o desenvolvimento do leitor a partir de uma notícia. In: Anais do II Seminário Nacional em Estudos da Linguagem: Diversidade, Ensino e Linguagem, Unioeste - Cascavel / PR, 2010.

POERSCH, José Marcelino. Uma questão terminológica: consciência, metalinguagem, metacognição. In: Revista Letras de Hoje. v. 33, n. 4, dez/1998. Porto Alegre: Edipucrs, 1998.

RICKHEIT, G.; STROHNER, H. Grundlagen der kognitiven Sprachverarbeitung. Cambridge: University, Press, 1993.

SCHMIDT, Siegfried J. Linguística e Teoria de Texto. São Paulo: Pioneira, 1978.

SIM-SIM, Inês. O Ensino de Leitura: a compreensão de textos. PNEP. Direcção de Inovação e Desenvolvimento Curricular do Ministério da Educação de Lisboa, 2007 (Col. Educação).

SIM-SIM, Inês. Desenvolver a linguagem, aprender a língua. In: CARVALHO, Adalberto Dias de (org.). Novas metodologias em educação. Lisboa: Porto Editora, 2002. p. 197-226. (Col. Educação, n. 8).

SMITH, Frank. Leitura Significativa. 3 ed. Porto Alegre: Artes médicas, 1999.

SOLÉ, Isabel. Competencia lectora y aprendizaje. Revista Iberoamericana de Educación, n. 59, 2012. p. 4361 (1022-6508) - OEI/CAEU.

SOLÉ, Isabel. Estratégias de leitura. 6. ed. Porto Alegre: ArtMed, 1998.

UCHOA, Sayonara Abrantes de Oliveira. Entre processos de significação e gatilhos de humor: aprendendo a ler na interação com o gênero tirinha. 2013. Dissertação (Mestrado) - Universidade Federal da Paraíba - UFPB, João Pessoa, 2013.

VASCONCELOS, Leila Janot de.; DIONÍSIO, Angela Paiva. Multimodalidade, capacidade de aprendizagem e leitura. In: BUNZEN, Clécio; MENDONÇA, Márcia (orgs.). Múltiplas linguagens para o ensino médio. São Paulo: Parábola Editorial, 2013, p. 43-67. 